\title{
ARTICLE OPEN The changing validity of tropical cyclone warnings under global warming
}

\author{
Nam-Young Kang ${ }^{1}$ and James B. Elsner ${ }^{2}$
}

Hurricanes and typhoons are a regular threat to large populations across the globe. Facing the potential of a storm disaster the warning process and associated administrative activities across the western North Pacific are confounded by various tropical cyclone classifications. Here, we show that current storm warning categories have suffered from the warming environment over the past decades. Warning now at an average of one out of four storms, the category of "Super typhoon" from U.S. Joint Typhoon Warning Center is seriously influenced by the warming environment. The categories of "Very strong typhoon" from Japan Meteorological Agency, "Hurricane category 4" from U.S. National Hurricane Center and the higher now occur as often as one per nearly every three storms. The cumulative proportions of storms falling into all warning categories are enlarging, which is interpreted as an increasing threat but the frequency of warnings is potentially making the warnings less effective.

npj Climate and Atmospheric Science (2018)1:36; doi:10.1038/s41612-018-0047-3

\section{INTRODUCTION}

Tropical storms have different names depending on the regional ocean basins where they form but everywhere they are the most threatening events in nature. ${ }^{1}$ Energetics involving a tremendous amount of water substantiate their thermodynamic potential for destruction. ${ }^{2,3}$ The western North Pacific is the largest storm reservoir, where as many as one-third of all global tropical cyclones (TCs) are spawned. This fact coupled with significant economic activity and a large population at risk creates a situation where catastrophes are frequently unavoidable. Making matters worse, there are several competing TC classifications used to communicate the threat by administrative authorities in this region. ${ }^{4}$ For example, observations from the Japan Meteorological Agency (JMA) and the U.S. Joint Typhoon Warning Center (JTWC) are widely utilized to interpret the danger of the storms. Owing to distinct observational procedures, 5,6 however, the comparison of warning categories within the TC classifications among those agencies remain a challenge. Wind speed in JMA best-track data is the value averaged over a 10-min period, while wind speed in JTWC best-track data is the value averaged over a 1-min period. This creates inconsistent intensity levels and makes comparing warning levels hard. ${ }^{7}$ Saffir-Simpson's hurricane intensity scale, used for North Atlantic and eastern North Pacific TCs, is often suggested as a reference for the intensity levels but this results in even greater confusion regarding storm warnings.

Recent findings on the connection between TCs and global warming seem to add to the confusion. Bursting intensification by the warming oceans is observed most significantly in the western North Pacific but it occurs throughout the tropics. ${ }^{9}$ The warning level of intensity categories in the TC classifications might be compromised by this warming environment, and the validity of the warning level has yet to be considered under this changing environment.

\section{RESULTS}

Storm intensities observed from different meteorological agencies For this study, TC is defined as a storm whose lifetime-maximum intensity (LMI) exceeds $34 \mathrm{kt}$, and the LMIs per TC over the past 30 years (1986-2015) are extracted from the two best-track data sets. JMA and JTWC best-track data record TC winds at 5-kt intervals, respectively as $10-\mathrm{min}$ and $1-\mathrm{min}$ average values. Only the reliability of the research findings could be enhanced by the observational consistency between the different observations. For this, the comparable intensities are sought from the two observations. It is somewhat common to match the LMI in JTWC with 1.2 times $^{10}$ of that in JMA, but this does not work well across all intensity levels. ${ }^{5,6}$ Elsner et al. ${ }^{11}$ introduced a quantile approach to the analysis of LMI, and Kang and Elsner ${ }^{7}$ employed the same idea for matching the intensities between the two best-track data. The fundamental assumption is that an intensity event share the same probability level even in different observations though recorded as having different absolute magnitudes. In this study, the inverse empirical cumulative distribution function (ECDF) is employed to find the probability level of the quantile. Here, the probability level of an LMI is defined by the cumulative proportion inversely from the highest LMI (see Supplementary Fig. S1). Figure 1 shows the probability level of LMI at 10-kt intervals in JMA and JTWC. Each black dot represents the 30-yr (1986-2015) mean of annual cumulative proportions. Probability-Probability (P-P) plots are normally used to evaluate the skewness of a distribution. As 1min average wind should allow larger spread than 10-min average wind, the range of JTWC is larger than that of JMA. This makes the dots digress from a diagonal line of the same probability level. Now that the probability level of storm intensity is identified, the warning categories in the TC classifications from the two besttrack data sets can also be compared.

\footnotetext{
${ }^{1}$ National Typhoon Center, Korea Meteorological Administration, Seoul, South Korea and ${ }^{2}$ Department of Geography, Florida State University, Tallahassee, FL 32306, USA Correspondence: N-Y. Kang (nkang.fsu@gmail.com)
}

Received: 4 April 2018 Revised: 5 August 2018 Accepted: 17 September 2018

Published online: 21 November 2018 


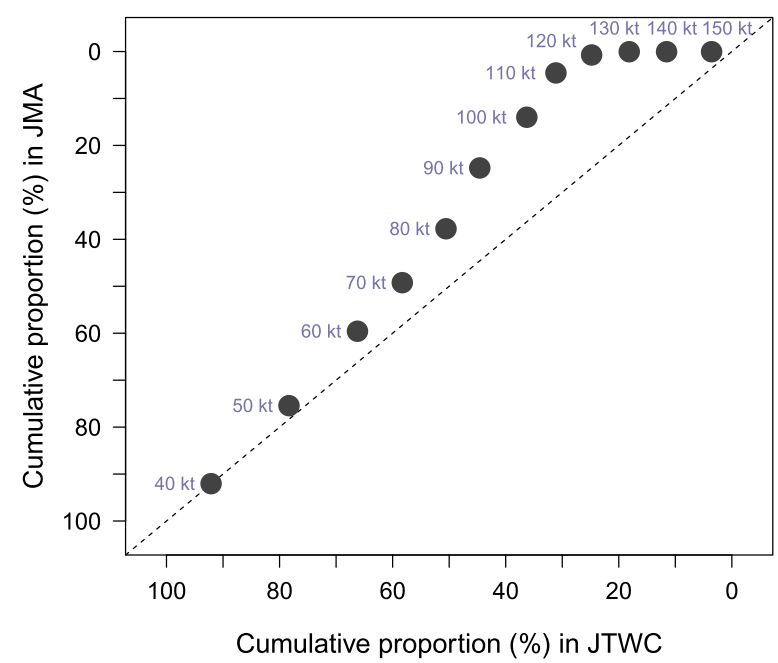

Fig. 1 Probability-Probability (P-P) plot of the LMls at 10-kt intervals in JTWC and JMA best-track data. Each black dot represents the 30yr (1986-2015) mean of annual probability levels. Probability level is calculated by the cumulative proportion inversely from the highest LMI. The dashed diagonal line draws the matching probability level of the TC intensities between JTWC and JMA

\section{Overcoming climate change perspective}

To see the response of the probability level of LMI to global warming, global mean SST (GMSST) can be used as a direct indicator of the warming environment., ${ }^{9,12}$ GMSST represents the annual variation of the global ocean warmth. As Bjerknes feedback works along, ${ }^{13}$ annual variation of GMSST shows a fluctuation similar to ENSO variation on relatively shorter timescale. At the same time, the forced increase is seemingly apparent on relatively longer timescales. ${ }^{12}$ Here, GMSST implies not merely a single physical parameter, but the indication of a synthetic environment where all environmental factors are constrained by the warmth level. The understanding of the environmental factors has been in progress, dealing with regional SST, vertical wind shear, vorticity, stability, and so forth. ${ }^{14,15}$ Figure 2 shows the correlation

coefficients of the annual cumulative proportions with time and GMSST, respectively. Positive sign indicates an increasing portion of TCs whose LMI exceeds the threshold value. Considering the fact that the correlation coefficient is the same as the regression coefficient when both the predictor and the predictand are standardized, the response to time (linked black dots) could be understood as the standardized amount of climate change. Each shaded area shows the $95 \%$ confidence interval and confirms that a statistically significant change is rarely captured even at the strongest LMI range. The response of the cumulative proportions to GMSST (linked orange dots), on the other hand, is found to be clearer than to time. In both best-track data sources, statistically significant correlation appears for the cumulative proportions around $40 \%$ and less, which means the stronger TCs are more responsive. ${ }^{11}$ As long as the $30-y r$ GMSST reflects the forced warming, the result implies that the simpler "climate change" approach to TC intensity using only time might weaken the global warming signal.

\section{Quantified worsening of storm warning validity}

Now, we examine and compare the influence of GMSST increase on the storm warning categories also shown using JTWC observation to further understand the validity of the storm warning categories. Firstly, the level of warning categories by $30-\mathrm{yr}$ mean of the cumulative proportions at each threshold LMI, are compared among the three different sources. Warning categories of JMA, JTWC, and SS are divided into four, three and six intervals, a JMA best track

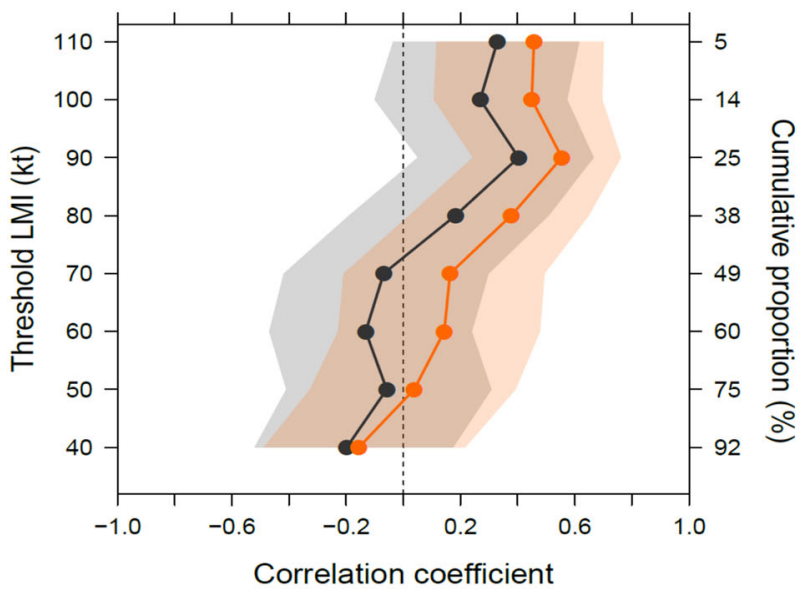

b JTWC best track

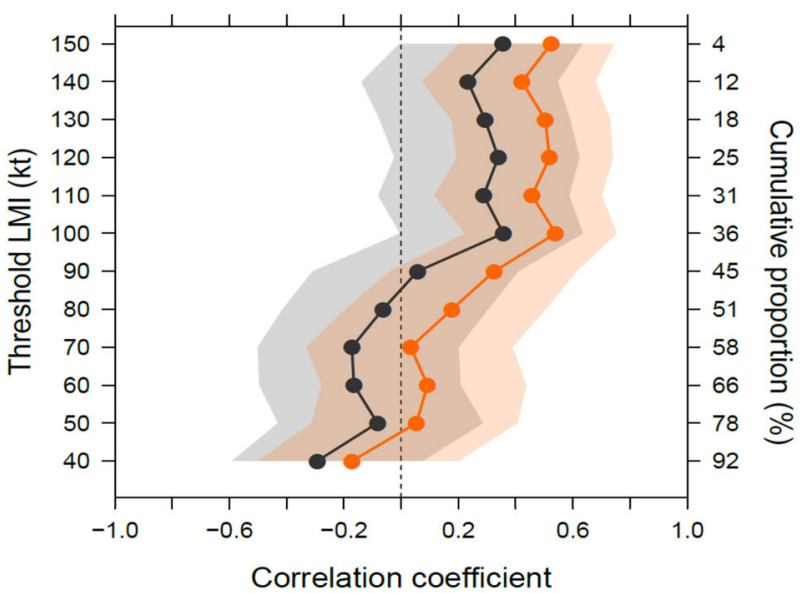

Fig. 2 Correlation coefficients of the annual probability levels of LMI with time (linked black dots) and GMSST (linked orange dots). The annual probability level means the annual variation of the cumulative proportion at each threshold LMI. Observations come from a JMA and b JTWC, respectively. Ninety-five percent confidence intervals are shaded in gray and orange colors for time and GMSST, for each. The average of the annual probability levels is labeled on the right ordinate

respectively (Table 1). The cumulative proportion method reveals that "Super typhoon" is not the highest level of warning. "Violent typhoon" in JMA ranks at the highest warning category covering only 7\% of the strongest storms. "Super typhoon" in JTWC and "Hurricane category 5 " in SS, on the other hand, represent $18 \%$ and $12 \%$, respectively. "Very strong typhoon" in JMA and "Hurricane category 4" in SS are comparable as covering each $31 \%$ and $29 \%$.

Secondly, binomial logistic regression is employed to model the cumulative proportion of LMIs on GMSST. Since the probability level ranges from 0 to 1 , the logit is used as the link function in the generalized linear model (GLM). For the cumulative proportion as the dependent variable, "success" is defined as the number of annual TCs over the threshold LMI inclusive, and "failure" is defined as all the rest. GLM assumes a linear relationship between the nonlinear link function and GMSST. In spite of the "global warming hiatus", meaning a pause between 1998 and 2013, ${ }^{16}$ the increase of GMSST is seen as ongoing. ${ }^{17}$ From a simple linear perspective, the increase of GMSST is significant as $+0.33 \pm 0.041$ (s.e.) ${ }^{\circ} \mathrm{C} / 30 \mathrm{yr}$. Then the GMSST input as the single explanatory variable is produced by the prediction of linear model over the 30 
Table 1. TC classifications for JMA, JTWC, and SS

\begin{tabular}{lll}
\hline JMA & JTWC & SS \\
\hline Violent typhoon (7\%) & Super typhoon (18\%) & Hurricane category $5(12 \%)$ \\
Very strong typhoon (31\%) & Typhoon (64\%) & Hurricane category 4 (29\%) \\
Strong typhoon (55\%) & Tropical storm (100\%) & Hurricane category 3 (36\%) \\
Typhoon (100\%) & & Hurricane category 2 (46\%) \\
& & Hurricane category 1 (100\%) \\
\hline
\end{tabular}

Each 30-yr (1986-2015) mean of the cumulative proportions at threshold values of the LMI is denoted in parentheses. JMA is referenced by JMA best-track data following 10-min period for averaging winds, while JTWC and SS by JTWC best-track data following 1-min period. Values are rounded to the nearest whole number.

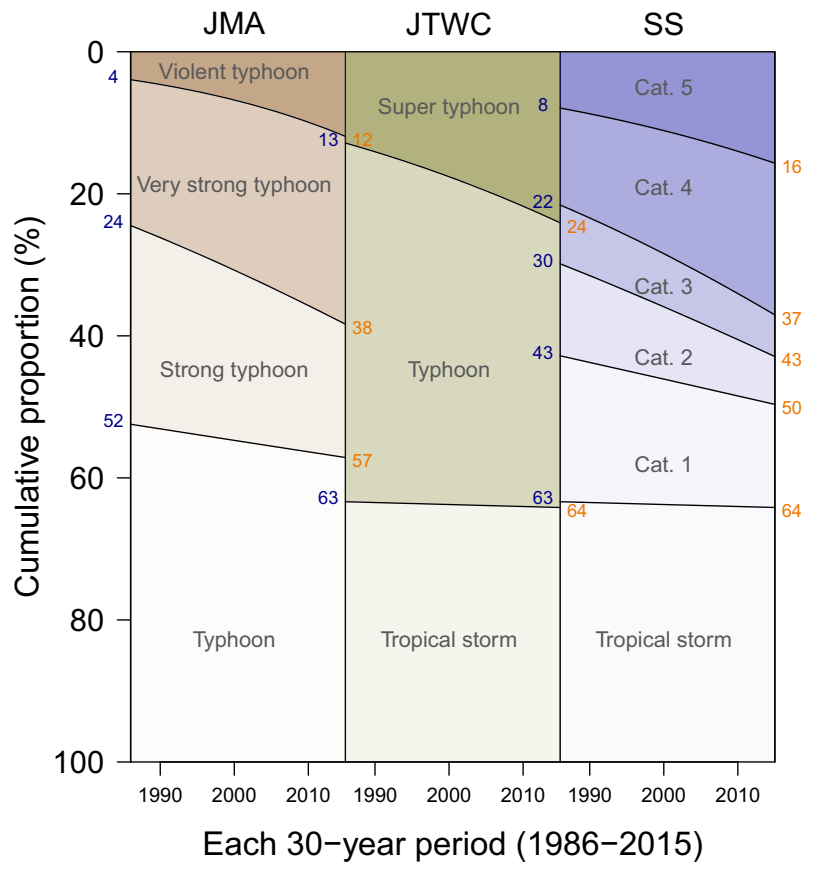

Fig. 3 Response of the probability level for the storm warning categories in the TC classifications to global warming. Binomial logistic regression is employed to model the probability level of the threshold LMls over the 30 years (1986-2015). Based on a linear assumption of global warming, the modeled GMSST by linear regression is used for the single explanatory variable. All results show significant responses to GMSST increase at $95 \%$ confidence level, except for the thresholds of "Typhoon" in JTWC and "Hurricane category 1" in SS. The storm warning categories for JTWC and SS are referenced by JTWC best-track data with 1-min average of the winds, which is different from JMA with 10-min average. Probability level indicated by the cumulative proportion, however, enables the comparison between the best-track data sets following different observational procedures. All values are rounded to the nearest whole number

years (1986-2015). On an assumption that the internal variation has no trend, the modeled GMSST implies the time series of GMSST where the internal variation is removed.

Based on this linear assumption of the global warming, modeled GMSST influence on the warning categories are shown in Fig. 3 (see Supplementary Fig. S2 for comparison with the prediction results by GLM on time). As the logistic regression works, the warning level for each category shows nonlinear change by GMSST change over the same period. All GLM results show significant responses to the increasing global ocean warmth at $95 \%$ confidence level, except for the thresholds of "Typhoon" in
JTWC and "Hurricane category 1" in SS (see Supplementary Table S1). Modeled cumulative proportion of the beginning year (1986) is denoted in dark blue color at the left side of each column, and that of the ending year (2015) in orange color at the right. All values are rounded off to the nearest whole number. Warning categories in all TC classifications are experiencing the increasing proportion, which is most apparent in the set of strongest storms. "Violent typhoon" in JMA started from 4\% and reached up to $12 \%$ over the 30 years. As the highest level among the warning categories, $12 \%$ could be considered as still being effective for rarely occurring extreme events. Nevertheless, the truth is that the warning for one per 25 storms in the past is not valid any longer. This is similar to the hurricane category 5 in SS, though the coverage is a bit larger than "Violent typhoon." The validity of "Super typhoon" is seen to be more seriously affected by global warming. The earlier $13 \%$ is changed to $24 \%$ by the end of the period, which means one per 4.2 storms making the word "super" seem somewhat misleading. Other categories also show widening ranges, though the gap looks less than that of the strongest categories. "Very strong typhoon" and "Hurricane category 4" added $14 \%$ and $15 \%$ more storms, each reaching $38 \%$ and $37 \%$. This implies that we see those warnings or more dire as often as one in every 2.6 and 2.7 storms. The larger proportion can be understood as representing the reality of the increasing threats, the frequency of warnings is, in practice, making the warning less effective. Overall, it seems clear that the validity of current warning categories are suffering from the warming environment.

\section{DISCUSSION}

On the basis of the observed TC intensity, meteorological agencies issue categorical storm warnings. But global warming appears to have influenced the TC intensity and the coverage of storm categories over the past 30 years. The value of this study lies in the fact that the influence of global warming on the warning categories in the TC classifications are quantitatively reviewed and compared. Results indicate that the current TC classifications are not valid for communicating the risk since we are warning considerably more often than before. The physical changes in the frequency of the strongest storms and the concominant societal shifts in response will continue as long as the warming continues. Recent studies on the increasing regional impacts by the changing climate and the TC intensity in the western North Pacific ${ }^{14,15}$ may support the importance of the review for better storm warning system. The findings discussed here should help inform and improve the warning procedures toward more efficient preparedness against these often catastrophic storms.

\section{METHODS}

Best-track data from JMA and JTWC are used to analyze the annual variation of the TC intensity and to review the TC classifications. The selection of the data period (1986-2015) is based on Kang and Elsner, ${ }^{7}$ 
who showed that the reliable consensus between the two agencies could be hampered when their observations prior to 1984 are included. They addressed that each of the termination of the U.S. Air Force aircraft reconnaissance, and the advanced techniques in the satellite observation on TCs might have negatively and positively affected the quality of intensity observation. A notable change, on the other hand, was found to have occurred in 1984 when JMA introduced the Dvorak intensity estimation technique ${ }^{18,19}$ to operational TC analysis (http://www.wmo. int/ pages/prog/www/tcp/documents/JMAoperationalTCanalysis.pdf). This implies that the sequence of JMA intensities since 1984 have been following a standardized analysis procedure. It was also remarked that the JTWC intensities prior to 1985 would be less reliable and need to be used with care..$^{20}$ In this study, the beginning year of the analysis is set as 1986 for a reliable consensus between JMA and JTWC.

\section{Code availability}

For study reproducibility, all of the statistics and figures are made by the software R (http://www.r-project.org) and code is available online (http:// rpubs.com/Namyoung/P2018b)

\section{DATA AVAILABILITY}

Best-track data for JMA and JTWC are available in http://www.jma.go.jp/jma/jma-eng/ jma-center/rsmc-hp-pub-eg/trackarchives.html and http://www.usno.navy.mil/

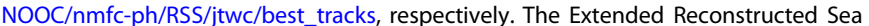
Surface Temperature version 4 (ERSSTv4) ${ }^{21}$ of the National Oceanic and Atmospheric Administration (NOAA)/National Centers for Environmental Prediction (NCEP) reanalysis (http://www.esrl.noaa.gov/psd/data/gridded) is used to identify the global ocean warmth.

\section{ACKNOWLEDGEMENTS}

This research was supported by the National Typhoon Center at the Korea Meteorological Administration ("Research and Development for Numerical Weather Prediction and Earthquake Services" project).

\section{AUTHOR CONTRIBUTIONS}

N.K. and J.B.E. contributed equally to planning, experiment, analysis and writing, with N.K. being the lead author.

\section{ADDITIONAL INFORMATION}

Supplementary information accompanies the paper on the npj Climate and Atmospheric Science website (https://doi.org/10.1038/s41612-018-0047-3)

Competing interests: The authors declare no competing interests.

Publisher's note: Springer Nature remains neutral with regard to jurisdictional claims in published maps and institutional affiliations.

\section{REFERENCES}

1. Natural Hazards. Unnatural Disasters: The Economics of Effective Prevention. (World Bank, United Nations, 2010)

2. Emanuel, K. E. Increasing destructiveness of tropical cyclones over the past 30 years. Nature 436, 686-688 (2005).

3. Mendelsohn, R., Emanuel, K., Chonabayashi, S. \& Bakkensen, L. The impact of climate change on global tropical cyclone damage. Nat. Clim. Change 2, 205-209 (2012).
4. World Meteorological Organization. Typhoon Committee Operational Manual: Meteorological Component 2017 Edition WMO TD-No. 196 (2017).

5. Knapp, K. R. \& Kruk, M. C. Quantifying interagency differences in tropical cyclone best-track wind speed estimates. Mon. Wea. Rev. 38, 1459-1473 (2010).

6. Song, J. -J., Wang, Y. \& Wu, L. Trend discrepancies among three best track data sets of western North Pacific tropical cyclones. J. Geophys. Res. 115, D12128 (2010).

7. Kang, N. -Y. \& Elsner, J. B. Consensus on climate trends in western north pacific tropical cyclones. J. Clim. 25, 7564-7573 (2012).

8. Simpson, R. H. The hurricane disaster potential scale. Weatherwise 27, 169-186 (1974).

9. Kang, N. -Y. \& Elsner, J. B. Trade-off between intensity and frequency of global tropical cyclones. Nat. Clim. Change 5, 661-664 (2015).

10. Atkinson, G. D. Investigation of gust factors in tropical cyclones. Joint Typhoon Warning Center Tech. Note. JTWC 74-1, 9 pp (Fleet Weather Central, US Navy, 1974).

11. Elsner, J. B., Kossin, J. P. \& Jagger, T. H. The increasing intensity of the strongest tropical cyclones. Nature 455, 92-95 (2008).

12. Kang, N. -Y. \& Elsner, J. B. Climate mechanism for stronger typhoons in a warmer world. J. Clim. 29, 1051-1057 (2016).

13. Bjerknes, J. A possible response of the atmospheric Hadley circulation to equatorial anomalies of ocean temperature. Tellus 18, 820-829 (1966).

14. Park, D. -S. R., Ho, C. -H. \& Kim, J. -H. Growing threat of intense tropical cyclones to East Asia over the period 1977-2010. Environ. Res. Lett. 9, 014008-014008 (2014). 20.

15. Park, D. -S. R. et al. Asymmetric response of tropical cyclone activity to global warming over the North Atlantic and western North Pacific from CMIP5 model projections. Sci. Rep. 7, 41354 (2017). 21.

16. Christensen, J. H. et al. in Climate Change 2013: The PhysicalScience Basis (eds Stocker, T. F. et al.) Ch. 14, 1248-1251 (IPCC, Cambridge Univ. Press, 2013).

17. Yang, S. -H., Kang, N. -Y., Elsner, J. B. \& Chun, Y. Influence of global warming on western North Pacific tropical cyclone intensities during 2015. J. Clim. 31, 919-925 (2018).

18. Dvorak, V. F. Tropical Cyclone Intensity Analysis and Forecasting from Satellite Visible Or Enhanced Infrared Imagery. Applications Laboratory Training Notes, 42 pp. (NOAA National Environmental Satellite Service, 1982).

19. Dvorak, V. F. Tropical Cyclone Intensity Analysis Using Satellite Data. NOAA Tech. Rep. 11, 45 pp. (1984).

20. Chu, J. H., Sampson, C. R., Levine, A. S., Fukada, E. The Joint Typhoon Warning Center tropical cyclone best tracks, 1945-2000. 22 pp. (Joint Typhoon Warning Center, 2002).

21. Huang, B. et al. Further exploring and quantifying uncertainties for Extended Reconstructed Sea Surface Temperature (ERSST) version 4 (v4). J. Clim. 29, 3119-3142 (2016).

Open Access This article is licensed under a Creative Commons Attribution 4.0 International License, which permits use, sharing, adaptation, distribution and reproduction in any medium or format, as long as you give appropriate credit to the original author(s) and the source, provide a link to the Creative Commons license, and indicate if changes were made. The images or other third party material in this article are included in the article's Creative Commons license, unless indicated otherwise in a credit line to the material. If material is not included in the article's Creative Commons license and your intended use is not permitted by statutory regulation or exceeds the permitted use, you will need to obtain permission directly from the copyright holder. To view a copy of this license, visit http://creativecommons. org/licenses/by/4.0/.

(c) The Author(s) 2018 